\title{
Revisiting the Newsvendor and Traveling Salesman in a Healthcare Disaster or Pandemic Response
}

\author{
Rebecca A. Scott \\ University of North Carolina Wilmington \\ Stephen Rutner \\ Texas Tech University
}

There are significant challenges to provide timely relief in healthcare disaster and pandemic response situations. The impact of these types of events risk large number of people to potentially fatal outcomes. A key element of providing timely relief is the distribution of critical medicines and supplies. Based on current literature, there appears to be a gap between simplistic solutions and complex optimization models. The goal of this paper is to provide a useful model that can be applied in time critical healthcare and pandemic situations.

\section{INTRODUCTION}

Healthcare related disasters have the ability to create vast amounts of destruction and provide a significant challenge to medical professionals, government and non-government organizations during a limited critical time period. The availability of medical supplies and inventory during an event remains a significant challenge to supply chain professionals and planners. The World Health Organization is unable to predict the length of time to for a pandemic to develop (Australian Government, 2010.) This further exacerbates inventory forecasting to determine the appropriate stock levels.

The challenge then becomes to react to a pandemic or similar mass casualty event in a timely manner with the appropriate medical supplies. There are three streams of literature that are helpful while examining this phenomenon. The first is supply chain agility or "Value chain" as it has been identified by Swafford et al. (2006). Also, Gligor and Holcomb (2012) provide a literature review that overviews the area of supply chain ability to react quickly in a possible pandemic like event will require an agile supply chain. A final portion of agility research deals with the complexity of the supply chain with numerous studies on the impacts of supply chain performance due to its complexity.

It is important to identify the value of the possible solution or tool that might be developed for the practitioner. The Centers for Disease Control and Prevention (CDC) lists three other pandemic flu occurrences since the 1918 Spanish Flu: 1957, 1968 and 2009. In the first two cases, there were over 1,000,000 fatalities world-wide each time. In 2009, the H1N1 virus infected over 60 million people and was responsible for 575,400 deaths worldwide (CDC, 2017.) The point that without timely intervention, to include the supply chain response, could have resulted in a pandemic. 
Therefore, it is critical that the healthcare supply chain be equipped with the tools and techniques to adequately respond to these situations. Currently, the United States system does a good job of providing "flu shots" to the populous during the peak periods of the year. While not perfect, the supply chain usually only suffers temporary shortages or stockouts (Dereyan, 2015.) But again, the flu vaccine supply chain is operating with a mostly known customer base and physical delivery system across the same few, known months each year.

\section{LITERATURE REVIEW}

Given the importance of the supply chain to react to an actual or a possible pandemic or pandemic like event, the agility of the supply chain becomes a critical factor in assessing its readiness. The supply chain literature on agility provides many useful models of the components that are needed to react to a dynamic market place. Most of these are transferable to not only the healthcare sector in general, but specifically situations that are often time critical and geographically remote. However, the models in the literature are very board and are building theory in most cases. While a few of the studies (E.g., Sharma, 2014 and Dhaigude, 2017) are applied, they too tend to validate theory with their models. The most recent example of Dubey et al. (2017) attempts to apply specific measure to agile supply chains, but is not fully developed in their conference proceeding. Therefore, there is a gap in the application of useful models that can help practitioners and academics to better address real world health types of crises.

While looking for useful tools for practitioners, a number of articles on healthcare disasters and humanitarian relief/disaster responsiveness provided a broad set of example type models. Ganguly et al. (2017) applied a fuzzy logic-based approach as a tool to help in the decision making process. Hale and Moberg (2005) also looked at preparation planning, storage site location, distance to event and inventory models. While those articles focus more on preparation, the goal of helping the healthcare responder has a slightly different stream of literature. Barbarosoglu et al. (2002) identified that the ability to react to a crisis in a timely manner would involve the use of various modes of transportation. Another approach was done by Afshar and Haghani (2012) when they modeled a real-time, large-scale disaster's relief operations. As the complexity of the models grow, the use of various forms of integer programing becomes problematic. The time, cost and complexity make many viable solutions useless in the real world setting. A different approach was done to examine emergency logistics response by Banomyong and Sopadang (2010.) While the previous models all attempted to find the optimized solution, their approach was to use Monte Carlo simulation to help refine the planning and preparation process. Most academics are attempting to create very complex and often all-encompassing solutions to the problem. The implication is that regardless of the topic, healthcare or sustainability, journal articles are tending towards complex solutions that may not be applicable to real-world, time-sensitive situations.

Based on the literature, the next logical step in the research was to determine if the gap in the literature is problematic to practitioners or not. Therefore, a series of interviews were conducted with various healthcare practitioners (supply chain and providers), first responders, military supply chain professional with relief experience, other governmental agency and finally non-government organizations. The series of interviews included what tools were they using and what types of tools would they likely use while doing relief planning and operations.

\section{RESEARCH QUESTIONS AND MODEL DEVELOPMENT}

Based upon gaps in the literature and responses from the practitioners, it became clear that there was an opportunity to develop a solution. This research analyzed this specific, critical situation and developed a mathematical framework using both the multi-product newsvendor and traveling salesman models to determine optimal ordering of perishable biopharmaceutical products while maximizing coverage as well as minimizing transportation costs. These models were chosen for a number of reasons: 1) both are well developed tools in the literature and in practice, 2) a combination should provide a better heuristic solution, and 3) any resulting solution should be easily adapted to the likely tools available to 
practitioners. The result would be to provide an improved process for medical facilities to use a quantitative model for quick justification to make order quantity decisions.

The objective of this research was to model the rapid inventory replenishment in the healthcare system when faced with a healthcare-related disaster. The two research questions were developed based on the literature and practitioner responses:

R1: how to determine optimal inventory levels of vaccines in order to prepare for distribution during a pandemic by using a multi-product newsvendor model

R2: how to apply those quantities into a traveling salesman model to maximize coverage while simultaneously minimizing transportation costs.

To address these research questions, a two-step approach was utilized to analyze rapid inventory replenishment. First, a multi-product newsvendor model was applied to find the optimum quantities of medication to minimize the shortage and surplus at each treatment center. Next, the optimal quantities were implemented into a traveling salesman problem to calculate the best possible coverage of a region while minimizing transportation costs. Using the multi-product newsvendor model allows for a mathematical option for healthcare administrators to analyze the optimal ordering quantity to achieve proper coverage. The follow up step of using the traveling salesman problem allows treatment centers to maximize coverage while minimizing transportation costs.

Assumptions

- Readily available vaccination

- Fully functional supply chain network

- Multiple mobile treatment centers in a region (i.e. DFW area)

- Cost of each vaccine is the same

- Penalty cost applies if there is a shortage (loss of life) or a surplus (wasted medicine) of vaccines at a mobile treatment center

- Demand is stochastic

Step 1 - Multi-Product Newsvendor

- $r=0,1,2 \ldots|R|=$ index of regions where $0=$ vaccine distributor

- $i_{r}=1,2, \ldots\left|I_{r}\right|=i^{\text {th }}$ treatment center of $r^{\text {th }}$ region; $i_{r}=\{(1,2$ for $r=1,2,3),(1$ for $r=0)$

- $p_{i_{r}}^{r}=$ Cost per unit of shortage of vaccine in each treatment center $i$ in region $r$

- $w_{i_{r}}^{r}=$ Shortage quantity of vaccine units in each treatment center $i$ in region $r\left(D_{i_{r}}^{r}-q_{i_{r}}^{r}\right)$

- $\quad v_{i_{r}}^{r}=$ Cost per unit of holding vaccine in each treatment center $i$ in region $r$

- $\quad z_{i_{r}}^{r}=$ Excess quantity of vaccine units in each treatment center $i$ in region $r\left(q_{i_{r}}^{r}-D_{i_{r}}^{r}\right)$

- $\quad c_{i_{r}}^{r}=$ Cost per unit of vaccine in each treatment center $i$ in region $r$

- $q_{i_{r}}^{r}=$ Quantity of vaccine capacity acquired by each treatment center $i$ in region $r$

- $\quad D_{i_{r}}^{r}=N\left(\mu_{i_{r}}^{r},\left(p_{i_{r}}^{r}\right)^{2}\right)$ demand follows normal distribution with mean $\mu$ and standard deviation $\sigma$ in each treatment center $i$ in region $\mathrm{r}$

Stage 1:

$\left(q_{i_{r}}^{* r}\right)=\arg \min \left(q_{i_{r}}^{r}\right)$

s.t $\quad q_{i_{r}}^{r} \geq 0$ 
Stage 2:

$\Pi=\operatorname{Min} . v_{i_{r}}^{r} z_{i_{r}}^{r}+p_{i_{r}}^{r} w_{i_{r}}^{r}$

s.t. $\quad z_{i_{r}}^{r} \geq q_{i_{r}}^{r}-D_{i_{r}}^{r} \quad \forall r \neq 0$

$w_{i_{r}}^{r} \geq D_{i_{r}}^{r}-q_{i_{r}}^{r} \quad \forall r \neq 0$

$z_{i_{r}}^{r}, w_{i_{r}}^{r}, q_{i_{r}}^{r} \geq 0, \quad \forall r$

where, $G\left(q_{i_{r}}^{r}\right)=E[\Pi]+\sum_{r=1}^{|R|} \sum_{i=1}^{|I|} c_{i_{r}}^{r} q_{i_{r}}^{r}$

Step 2 - Traveling Salesman Problem

- $r=0,1,2 \ldots|R|=$ index of regions where $0=$ vaccine distributor

- $i_{r}=1,2, \ldots\left|I_{r}\right|=i^{\text {th }}$ treatment center of $r^{\text {th }}$ region; $i_{r}=\{(1,2$ for $r=1,2,3),(1$ for $r=0)$

- $q_{i_{r}}^{* r}=$ Optimal quantity of the vaccine needed in each treatment center $i$ in region $r$

- $m_{i_{r}, j_{r}}^{r}=\{(1$ if treatment center $j$ is immediately followed by treatment center $i$ in a route $),(0$ otherwise)

- $d_{i_{r}, j_{r}}^{r}=$ Distance of treatment center $i$ from treatment center $j$

- $\sum_{r=1}^{3} \sum_{i=1}^{2} q_{i_{r}}^{r}=K=$ Maximum capacity of the small fleet per treatment

- $n_{i_{r}}^{r}=$ Total amount of vaccine delivered on the route that includes up to treatment center $i$ in region $r$ including treatment center $i$

$Z=\operatorname{Min} . \sum_{r=0}^{3} \sum_{i_{r}}^{\left|I_{r}\right|} d_{i_{r}, j_{r}}^{r} m_{i_{r}, j_{r}}^{r}$

s.t. $\quad \sum_{r=0}^{3} \sum_{i_{r}}^{\left|I_{r}\right|} m_{i_{r}, j_{r}}^{r}=1, \quad \forall_{j_{r}}$

$\sum_{r=0}^{3} \sum_{i_{r}}^{\left|I_{r}\right|} m_{i_{r}, j_{r}}^{r}=1, \quad \forall_{i_{r}}$

$q_{i_{r}}^{* r} \leq n_{i_{r}}^{r} \leq K, \quad \forall_{i_{r}}$

$n_{i_{r}}^{r} \leq K+\left(q_{i_{r}}^{* r}-K\right) m_{i_{r}, j_{r}}^{r}, \quad \forall_{i_{r}}$

$n_{j_{r}}^{r} \geq n_{i_{r}}^{r}+q_{j_{r}}^{* r}-K+K m_{i_{r}, j_{r}}^{r}+\left(K-q_{j_{r}}^{* r}-q_{i_{r}}^{* r}\right) m_{i_{r}, j_{r}}^{r}, \forall_{i_{r}, j_{r}}$

$n_{i_{r}}^{r} \geq 0, \quad \forall_{i_{r}}$

$m_{i_{r}, j_{r}}^{r} \in\{0,1\}, \forall_{i_{r}, j_{r}}, i_{r} \neq j_{r}$

The result of the two step approach is to provide a relatively simple new mathematical basis that can be quickly and easily inputted into Excel or other common spreadsheet software by practitioners to dramatically improve stock levels and replenishments. The goal of this article is to begin the discussion and more refine the model for application. 


\section{DISCUSSION}

The two step approach of applying the models creates an opportunity for users. The relatively simple computation is easily inputted into a spreadsheet for use. Furthermore, it can be quickly applied to unique, real world situations. In contrast, many of the literature review articles provide very specific geographic conditions that are too restrictive for use in other situations. Using a simplistic mapping tool or applying the grid method with the developed model could provide emergency and relief workers a better tool to make important decisions in a limited time and information environment.

Due to the two stage model develop process, the model addresses the key research questions. The first stage of the model helps to better determine inventory levels to meet the overall needs of the specific situation. The second stage of the model then allocates that inventory in an efficient method to maximize usage while minimizing cost. It should be noted that a simple substitution of time or distance could be substituted for cost in specific cases. For example, in extreme pandemic circumstances cost would likely not be an issue. Therefore, time and distance could be used to more rapidly distribute needed medicines. Regardless of the cost or time decision, the two stage model provides a better solution than simple heuristics. The resulting model begins an examination of providing a better method to help aid workers in time, cost, crisis situations.

\section{LIMITATIONS AND FUTURE OPPORTUNITIES}

There are two significant limitations of the research in its current form. First, the model attempts to balance complexity with ease of use. Therefore, it is unlikely that this provides the best solution. The second challenge is that the model has not been tested in either a modeled simulation or real-world situation. However, this may present a future opportunity to compare the solution to existing, optimization models. This would provide a basis for comparison to determine if the two stage model's solution is adequate while being significantly more easily applied. Finally, once it is validated it would have to be simplified, inputted to Excel and provided to aid workers. The most likely solution would be an add-on that simplifies the process for potential users.

\section{CONCLUSIONS}

The goal of the paper was to begin the process of developing a useful model for relief workers balancing the limited resources of time, delivery and materials in a crisis situation. The two step model provides a better solution of the likely "winging it" mentality of low tech solution providers (i.e., typical aid workers with limited budgets and computation power). The value of the two step model is that it helps to bridge the gap from limited computation options to excessively complex solutions. While it solves the problem with a sequential approach, it provides a seamless, single model to the user(s) to better allocate limited resources in a critical situation. The hope of the authors, who have worked in relief operations, is to find a tool that can be used by normal relief type workers with limited assets. Furthermore, this paper is the first step in a process to continue to refine the model and develop a working tool for users. 


\section{REFERENCES}

Afshar, A., \& Haghani, A. (2012). Modeling Integrated Supply Chain Logistics in Real-Time Large-Scale Disaster Relief Operations. Socio-Economic Planning Sciences, 46, 327-338.

Ahmadi, M., Seifi, A., \& Tootooni, B. (2015). A Humanitarian Logistics Model for Disaster Relief Operation Considering Network Failure and Standard Relief Time: A Case Study of San Francisco District. Transportation Research Part E: Logistics and Transportation Review, 75, 145-163.

Argollo da Costa, S.R., Campos, V.B.G., \& Bandeira, A. (2012). Supply Chains in Humanitarian Operations: Cases And Analysis. Procedia - Social and Behavioral Sciences, 54(4), 598-607.

Australian Government, Department of Health (2010). How does a Pandemic Develop? Retrieved April 12, 2018, from www.health.gov.au/internet/main/publlishing.nsf/Content/about-pandemic-howdevelop

Banomyong, R., \& Sopadang, A. (2010). Using Monte Carlo Simulation to Refine Emergency Logistics Response Models: A Case Study. International Journal of Physical Distribution \& Logistics Management, 40(8/9), 709-721, https://doi.org/10.1108/09600031011079346

Barbarosoglu, G., Ozdamar, L., \& Cevik, A. (2002). An Interactive Approach for Hierarchical Analysis of Helicopter Logistics in Disaster Relief Operations. European Journal of Operational Research, 140, 118-33.

Billings, M. (2005). The Influenza Pandemic of 1918. Retrieved April 13, 2018, from https://virus.stanford.edu/uda/

Brandenburg, M., Govindan, K., Sarkis, J., \& Seuring, S. (2014). Quantitative Models for Sustainable Supply Chain Management: Developments and Directions. European Journal of Operational Research, 233(2), 299-312.

Centers for Disease Control and Prevention (2017). Past Pandemics. Retrieved April 11, 2018, from https://www.cdc.gov/flu/pandemic-resources/basics/past-pandemics.html

Chan, E. (2016, December 26). Biological Weapons of Mass Destruction with the Ability to Spread Deadly Diseases like Ebola and Zika 'could wipe out up to a fifth of the world's population'. Daily Mail. Retrieved April 13, 2018, from www.dailymail.co.uk/news/rticle4066952/biological-weapons-mas-destruction-ability-spread-deadly-diseases-like-Ebola-Zikawipe-fifth-world-s-population.html

Cozzolino, A., Rossi, S., \& Conforti, A. (2012). Agile and Lean Principles in the Humanitarian Supply Chain: The Case of the United Nations World Food Programme. Journal of Humanitarian Logistics and Supply Chain Management, 2(1), 16-33. https://doi.org/10.1108/20426741211225984

Dereyan, A. (2015, December 29). Flu Vaccine Supply Chain Changes Needed to Stop Shortages. Pharmacy Times. Retrieved April 11, 20018, from www.pharmacytimes.com/resourcecenters/flu/flu-vaccine-supply-chain-changes-needed-to-stop-shortages

Dhaigude, A., \& Kapoor, R. (2017). The Mediation Role of Supply Chain Agility On Supply Chain Orientation-Supply Chain Performance Link. Journal of Decision Systems, 26(3), 275-293. DOI: $10.1080 / 12460125.2017 .1351862$

Dubey, R., Gunasekaran, A., \& Childe, S. J. (2018). Big Data Analytics Capability in Supply Chain Agility: The Moderating Effect of Organizational Flexibility. Management Decision. https://doi.org/10.1108/MD-01-2018-0119

Dushoff, J., Plotkin, J. B., Viboud, C., Earn, D., \& Simonsen, J.D. (2006). Mortality due to Influenza in the United States - An Annualized Regression Approach Using Multiple-Cause Mortality Data. American Journal of Epidemiology, 163(2), 181-187.

Ganguly, K. K., Padhy, R.K., \& Rai, S. S. (2017). Managing the Humanitarian Supply Chain: A Fuzzy Logic Approach. International Journal of Disaster Resilience in the Built Environment, 8(5), 521-536. https://doi.org/10.1108/IJDRBE-07-2015-0038 
Gligor, D. M. (2014). The Role of Demand Management in Achieving Supply Chain Agility. Supply Chain Management: An International Journal, 19(5/6), 577-591. https://doi.org/10.1108/SCM10-2013-0363

Gligor, D. M., \& Holcomb, M. C. (2012). Understanding the Role of Logistics Capabilities in Achieving Supply Chain Agility: A Systematic Literature Review. Supply Chain Management: An International Journal, 17(4), 438-453.

Gligor, D. M., Holcomb, M. C., \& Stank, T. P. (2013, June). A Multidisciplinary Approach to Supply Chain Agility: Conceptualization and Scale Development. Journal of Business Logistics, 34(2), 94-108.

Hale, T., \& Moberg, C. R. (2005). Improving Supply Chain Disaster Preparedness: a Decision Process for Secure Site Location. International Journal of Physical Distribution \& Logistics Management, 35(3), 195-207. https://doi.org/10.1108/09600030510594576

Jemai, Z., Boubaker, S., Sahin, E., \& Dallery, Y. (2017). A New Metric to Evaluate the Supply Chain Agility. 7th International Conference on Industrial Engineering and Systems Management (IESM'2017), Oct 2017, Saarbrücken, Germany. https://hal.archives-ouvertes.fr/hal-01672406

Kilbourne E.D. (2004). Influenza Pandemics: Can We Prepare for the Unpredictable? Viral Immunol, 17(3), 350-357.

Kovacs, G., \& Spens, K. (2009). Identifying Challenges in Humanitarian Logistics," International Journal of Physical Distribution \& Logistics Management, 39(6), 506-528.

Lorena L.A.N., \& Lopes, F. B. (1994). A Surrogate Heuristic for Set Covering Problems. European Journal of Operational Research, 79, 138-150.

Manuj, I., \& Mentzer, J. T. (2008). Global Supply Chain Risk Management Strategies. International Journal of Physical Distribution \& Logistics Management, 38(3), 192-223.

Rennemo, S. J., Ro, K. F., Hvattum, L. M., \& Tirado, G. (2014). A Three-Stage Stochastic Facility Routing Model for Disaster Response Planning. Transportation Research Part E: Logistics and Transportation Review, 62(Feb), 116-135.

Roh, S., Jang, H., \& Han, C. (2013). Warehouse Location Decision Factors in Humanitarian Relief Logistics. The Asian Journal of Shipping and Logistics, 29(1), 103-120.

Rossetti, C.L., Handfield, R., \& Dooley, K.J. (2011). Forces, Trends, and Decision in Pharmaceutical Supply Chain Management. International Journal of Physical Distribution \& Logistics Management, 41(6), 601-622.

Sandelands, E. (1994). Replenishment Logistics Give Food for Thought. International Journal of Physical Distribution \& Logistics, 24(3), 17-18.

Sharma, S. K., \& Bhat, A. (2014). Modelling Supply Chain Agility Enablers Using ISM. Journal of Modelling in Management, 9(2), 200-214. https://doi.org/10.1108/JM2-07-2012-0022.

Swafford, P. M., Ghosh, S., \& Murthy, N. N. (2006). A Framework for Assessing Value Chain Agility. International Journal of Operations \& Production Management, 26(2), 118-140.

Tatham, P.H., \& Pettit, S.J. (2010). Transforming Humanitarian Logistics: The Journey to Supply Network Management. International Journal of Physical Distribution \& Logistics Management 40(8), 609-622.

Verbic, M. (2006). Discussing the Parameters of Preservation of Perishable Goods in a Cold Logistic Chain Model. Applied Economics, 38(2), 137-147. 